\title{
Cultural Differences Influence on Language
}

\author{
Xiao Geng \\ Qingdao University of Science and Technology \\ Qingdao 266003, China \\ E-mail: gxdonna@gmail.com
}

\begin{abstract}
Language reflects a nation's characteristic and contains historical and cultural backgrounds of the nation. So language is closely attached to language. Cultural influence on language mainly embodies in cultural differences, which is emphasized in this paper.
\end{abstract}

Keywords: Culture, Difference, Influence, Language

\section{Introduction}

It is a common fact that in our foreign language teaching, we are not only taught language itself but also we are taught culture of that nation. Language stores all the social lives and experience of a nation, and reflects all the characteristics of a nation's culture. When a child learns a language of a nation, at the same time, he is learning the culture of the nation. If a person is not familiar with the culture of a nation, he can't learn the language of the nation well. Language is inextricably bound up with culture. Culture values are both reflected by and carried through the language.

From the above, we can know the importance of culture for the language.

\section{Cultural differences cause language differences}

Every nation has its own way of viewing the universe, and each develops from its own premises a coherent set of rules, which will be handed down from generation to generation.

Gradually, they are accepted as the essential part in people's life. This is the formation of culture.

Since the social background and geographic situations are different from nation to nation or even from place to place in the same country, cultures in different nations have more differences, less similarities. Cultural influence on language mainly embodies in cultural differences' influence on language. So, I will put emphasis on cultural differences' influence on language.

\subsection{Geographic situations}

In England, one can experience almost every kind of weather except the most extreme. You never can be sure when the different types of weather will occur. Not only do we get several different sorts of weather in one day. But, we may very well get a spell of winter in summer and vice-versa. This uncertainty about the weather has had a definite effect upon the Englishman's language.

The geographic situations on the language can be testified by the following example. In Chinese opinion, the east wind stands for warmness, spring and also the beautiful things. One Chinese poem used to be translated as following:

Hard it was to see each other

Harder still to part!

The east wind has no force

The hundred flowers wither

It's difficult for to meet and to part

The east wind too weak to revive, flowers dead.

The Englishman finds it hard to understand. Because according to England's location, in their eyes, the east wind should be bitter cold wind while the west wind symbolizes warmness. Like John Mansfield's famous poem "Ode to the west wind".

It's a warm wind, the west wind, full of bird's cries, 
I never hear the west wind but tears are in my eyes,

For it comes from the west I ands, the old brown hill,

And April's in the west wind, and daffodils. The different understanding towards west winds and east winds between the westerners and Chinese is caused by the influences of culture on language. According to England's location, west wind can bring warmness to them while in China, east winds can bring warmness to us. So, in English, they use west wind to stand for the beautiful things, while in China, we use east winds to stand for beautiful things.

\subsection{Social backgrounds}

\subsubsection{Relative relations}

China is a country with five thousand years history book. And also Confucianism plays an important part in Chinese history. The Chinese distinguish their relative relations seriously. This is caused by the feudalism culture. In this culture, any social relationship must be stipulated by the relative titles. No matter it is funeral or wedding or inherit the heritage, it must be done according to the relative tree.

In traditional Chinese family, there are usually a large members of people, including uncles, aunts, brothers, and sisters, etc. so they tell "ge ge" from "didi", and also tell from "meimei"to "jiejie". In traditional English family, they are nuclear family, only the parents and their children live together. So they don't tell "shushu" from "bobo", not because they don't do so, but because on most occasions, they don't have to. The feudal culture enriches the Chinese vocabulary, and causes more Chinese words about relative titles. And also because of the influence of western culture, English don't have many words about relative titles.

\subsubsection{Social conditions}

China is an agricultural nation, agriculture plays a very important part in the daily life of Chinese people. The feature can also be reflected in our Chinese language. So there are manysentences related to agriculture in our Chinese, for example, "xie jie gui tian", "tao li man tian xia", and so on. These all attribute to the influence of Chinese culture.

The English history is an invasion history, it invades many countries in the history, and it used to be called "The sun never setting empire". The Englishmen used to defeat the "Invincible fleet" of Spanish in Elizabeth age on the sea and become the strongest country in the world at that time. So there are some English languages related to sea and fishing like "be all at sea", "know the ropes". While the language related to agriculture is rare.

\subsubsection{Human relationships}

One important factor to maintain harmonious relationships with others is to be polite with others. There is a little difference in the usage of polite words between Chinese and English. Though it is true that in every culture, people use polite language to be polite, when and what to say make differences. It can be very impolite not to add the polite words when one is supposed to. Take "Thank you" for example. In Chinese culture people will only say "xie xie", the Chinese equivalent of "Thank you". When they receive help from others, and if it is only a minor help, people always omit that. However, in western countries, it is used in a much broader context. Except from getting help, they use it in occasions like buying things, receiving a call, or just for the attendances in a party. It sometimes puzzles the Chinese, when a westerner says 'thank you" after we sell things to them. For we think it should be we who need to say that, and we sometimes respond that "thank me for what". This kind of misunderstanding is due to the ignorance of other's culture. In fact, "thank you" for westerners does not only show the gratitude in our understanding, rather, it has been used as a custom and of course, they sometimes are prepared for the others to say that. If we treat this situation the same as we Chinese do, it will not be very polite. There is another point regarding to the difference in using "Thank you".

We Chinese will not use it or use fewer as a sign of intimate relations and just bear the gratitude in mind. For Chinese are more introverted in showing feelings. However, in western countries, people are more open in showing feelings, so they will not omit that even to their parents. This different language expression concerning polite words is caused by the different culture.

\subsection{Cultural pattern}

Cultural patterns address the manner in which a culture orients itself to activities, social relations, and the world. In studying cultural differences, many researchers cite the concept of "cultural patterns". Hofstede present that there are five primary differences in cultural patterns. I will also discuss cultural patterns influence on language from these five aspects. 


\subsubsection{Power distance index}

Power distance index focuses on the degree of equality or inequality, between people in the countries. A high power distance ranking indicates that inequalities of power and wealth have been allowed to grow within the societies. These societies are more likely to follow a system that does not allow significant upward mobility of its citizens. A low power distance ranking indicates the society de-emphasize the differences between the citizen's power and wealth. In these societies, equality and opportunity for everyone is stressed. Because of the influences of feudalism culture, China is a high power distance ranking nation. Just because of this, the saying "xing bu shang dai fu, li bu xia su ren" appeared in Chinese. The American is a low power distance ranking nation, they say: Everyone is equal before the God. This is greatly influenced by their Christian culture.

\subsubsection{Individualism - Collectivism}

Hofstede defines individualism and collectivism as follows:

Individualism pertains to societies in which the ties between individuals are loose: everyone is expected to look after himself or herself and his or her immediate family. Collectivism as its opposites pertains to societies in which people from birth onwards are integrated into strong cohesive in-groups, which throughout people's life -time continue to protect them in exchange for unquestioning loyalty.

In individualistic cultures, like American, people are more self-oriented and the concepts such as "I", independence and self- reliance are emphasized, whereas in collective cultures, like China, they' are more group-oriented and the concepts such as "we" interdependence, duties, obligations, needs, and views of in-groups are valued. Individual goals are in ore important in individualistic societies than in collective societies while belonging to groups is emphasized more, in collective societies than in individualistic societies.

Individualism and collectivism exist in all cultures, members of individualistic cultures learn some collective values and acquire views of themselves as a unique person. But the language is influenced by the dominant cultural pattern of a nation. That is why we Chinese like to say "More people produce greater strength". And also in certain historical period, the language "eating over a big pot" occurred. The westerners say "God help those who help themselves." This is because their cultures emphasize the efforts of individuals, and this kind of culture influences the minds of the people, so the sentence occurred.

\subsubsection{Masculinity-Feminine}

Masculinity- feminine is also a cultural pattern, masculinity means culture in which the dominant values in a society are male oriented and is associated with such behaviors as ambition, sex rules, achievements and the acquisition of money. Feminine is a culture that man can assume nurturing roles and also promotes sexual equality. Masculinity focuses on the degree the society reinforces, or does not reinforce, the traditional masculine work role, model of male achievement and power. A high masculinity ranking indicates the country experiences a high degree of gender differentiation. In these cultures, males dominate the significant portion of the society and power structure with females being controlled by male domination. A low masculinity ranking indicates the country has a low level of differentiation and discrimination between genders. In these cultures, females are treated equally to males in all aspects of the society. In Chinese culture, though in recent years, the females gradually begin to request: equal work, equal pay. In the old society, the males control women, a husband can have several wives. The concept of "treatment of females as inferior to males" almost exists in everyone's heart. So there is the language "The man is the sky" in the past. The appearance of this sentence is caused by the old Chinese culture. In recent years, the women liberation movements begin to rise in western countries, the females required to have the same rights with the males. This can be reflected in their languages. In the past, there is only "chairman" "businessman" but in recent years "chairwoman" "businesswoman', also become very popular. While in China, we only have "zhuxi" "shang ren". And the women liberation movement also helped to the use of "their" in sentences like "Everyone has to do their job properly" more acceptable in preference to "his" and "his or her".

\subsubsection{Uncertainty avoidance}

It focuses on the level of tolerance for uncertainty and ambiguity within the society, unstructured situations. China is a nation whose culture is characterized by high uncertainty avoidance. They feel especially anxious about the uncertainty in life and try to limit and control it as much as possible. They have more laws, regulations, policies, and procedures and a greater emphasis on obeying them. They also have a strong tendency toward conformity hence predictability. People take comfort in structure, systems.

America is a nation whose culture is characterized by low uncertainty avoidance. People there do not feel so threatened nor anxious about uncertainty, and therefore do not have such a strong need to limit or control it. They 
are curious rather than frightened by the unknown things or situations. This can be reflected in their language "Risks are opportunities" "conflict in organization is natural, nothing is to be afraid of" while we Chinese think "Difference is dangerous".

2.3.5 Time orientation

In Chinese culture, they believe strongly in a significance of prior advance. History established religions and traditions, so there is a strong belief that the past should be the guide for making decisions. We can know this from the saying "Consider the past, you'll know the present" America is a future-oriented nation, they emphasize the next thing and expected to be wonderful and nicer than the present. So the Americans like to say "I fat first you don't succeed, try, try, and try again.

\section{Conclusion}

From the above, we can come to the conclusion that: language is closely attached to culture. Culture contains language and influences language. Language is an important part of culture and also it is a necessary tool of maintaining culture, exchanging culture and reflecting culture.

Language and the use of language are not separable from culture. Our Chinese culture is quite different from that of western countries, culture differences cause language differences. In a word, culture influences language presentation.

\section{References}

Deng, Yanchang \& Liu Runqing. (1989). Language and Culture--Comparison between English and Chinese. Beijing Foreign Language Teaching and Research Press.

Gudykunst, W. B. Uncertainty and Anxiety Sage Publications.

Hofstede. Cultures and Organizations. Modern Press.

Hu, Wenzhong. (2004). Cross Culture and English Teaching. Shanghai Translation Press.

Hu, Zhuanglin, Liu, Runqing \& Li, Yanfu. (2001). Linguistics: a course book. Peking University Press.

Jin, Huikang. (2000). Cross Cultural Communication Translation. China's Foreign Translation Press. 